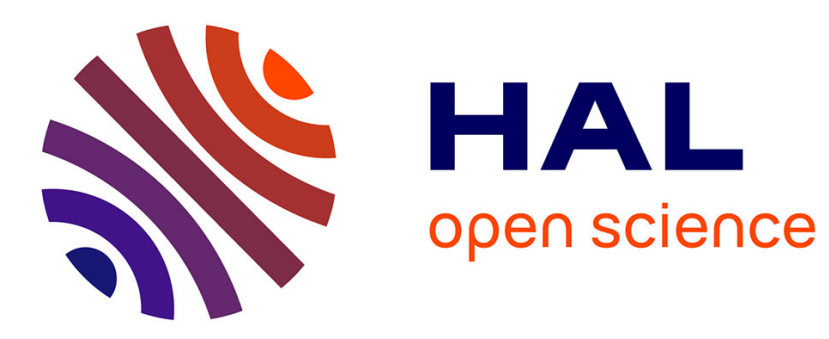

\title{
High-resolution elastic analysis of thin-ply composite laminates
}

\author{
Jihed Zghal, Amine Ammar, Francisco Chinesta, Christophe Binetruy, \\ Emmanuelle Abisset-Chavanne
}

\section{- To cite this version:}

Jihed Zghal, Amine Ammar, Francisco Chinesta, Christophe Binetruy, Emmanuelle Abisset-Chavanne. High-resolution elastic analysis of thin-ply composite laminates. Composite Structures, 2017, pp.12. 10.1016/j.compstruct.2017.03.083 . hal-02284774

\section{HAL Id: hal-02284774 https://hal.science/hal-02284774}

Submitted on 12 Sep 2019

HAL is a multi-disciplinary open access archive for the deposit and dissemination of scientific research documents, whether they are published or not. The documents may come from teaching and research institutions in France or abroad, or from public or private research centers.
L'archive ouverte pluridisciplinaire HAL, est destinée au dépôt et à la diffusion de documents scientifiques de niveau recherche, publiés ou non, émanant des établissements d'enseignement et de recherche français ou étrangers, des laboratoires publics ou privés. 


\title{
High-resolution elastic analysis of thin-ply composite laminates
}

Jihed Zghal $^{\mathrm{a}, \mathrm{b}}$, Amine Ammar ${ }^{\mathrm{b}}$, Francisco Chinesta ${ }^{\mathrm{c}}$, Christophe Binetruy ${ }^{\mathrm{a}}$, Emmanuelle Abisset-Chavanne ${ }^{\mathrm{c}}$

${ }^{a}$ GeM UMR CNRS-Centrale Nantes, 1 rue de la Noë, F-44300 Nantes, France

${ }^{b}$ LAMPA, Arts et Metiers Paris Tech, 2 Boulevard du Ronceray, 49035 Angers Cedex 01, France

${ }^{c}$ High Performance Computing Institute - ICI -, Centrale Nantes, 1 rue de la Nö, F-44300 Nantes, France

\begin{abstract}
Several studies showed that thin-plies composite laminates apparently exhibit higher strength than its counterpart using thicker plies. In this work, a high-resolution numerical discretization based on the use of in-plane-out-of-plane separated representations within the Proper Generalized Decomposition - PGD - framework is performed in different composites laminates for determining the effect of ply-thickness on the laminate stiffness. The results reveal that the global stiffness increases with the ply-thickness reduction. The analysis also reveals that this mechanical enhancement is due to structural effects and not to the mechanical confinement initially advanced.
\end{abstract}

Keywords: Thin-ply composite laminate, Composite performances, Advanced simulation, In-plane-out-of-Plane separated representation, Proper Generalized Decomposition - PGD

\section{Introduction}

Nowadays, in many engineering applications a compromise between high stiffness and lightweight design is searched. For this reason, in many engineering fields (aerospace, naval and automotive industries, among others) polymer composite laminates are being extensively used because they are viewed as key technology to develop energy efficient, cost-effective, lightweight, high-strength and stiffness parts.

Laminate made of thinner plies started to attract more attention in industrial applications because of its apparent performance enhancement while keeping constant the structural weight. Thus thin-ply laminates are commercially available, with thicknesses of about $20 \mu m$ or even lower depending of the type of fibers [1]. Many researches were carried out to characterize the resulting materials and structural parts. Many studies pointed out the fact that thin-ply composite laminates exhibit $10 \%$ higher ultimate strength resistance compared to

Email addresses: jihed.zghal@ec-nantes.fr (Jihed Zghal), Amine.AMMAR@ensam.eu (Amine Ammar), Francisco.Chinesta@ec-nantes.fr (Francisco Chinesta), christophe.binetruy@ec-nantes.fr (Christophe Binetruy), Emmanuelle.Abisset-chavannedec-nantes.fr (Emmanuelle Abisset-Chavanne) 
their counterpart with thicker plies (other things being equal) [17, 18]. In [15] authors showed that thin laminate composites have about $23 \%$ higher strength when they are subjected to compression after impact tests.

Most of these works focused on damage while considering different loading and stacking conditions $[18,15,10,6,16]$ where significant differences with respect to usual laminates making use of thicker plies were reported, and some damage mechanisms were advanced. While damage is likely to occur outside the elastic range, the present work only addresses the purely elastic response of composite laminates in order to check if the use of thin plies has an impact of the laminate stiffness and clarify the origin of this improved mechanical performance: does it come from the stress and strain confinement or is it due to a simple structural effect?

The finite element solution of elastic problems in a composite laminate does not seem challenging, however, a fine enough resolution requires using many nodes along the thickness direction able to capture all the solution details across the different plies of the laminate. Thus, one can face a strong limitation in the mesh refinement when using 3D discretization. High-resolution 3D simulation in composite laminates are quite rare in the literature and in our knowledge there are not detailed analyses when the plies-thickness becomes very thin because 3D mesh-based discretization techniques fail to compute the accurate solution of the mechanical problem. To alleviate this issue we proceed by using an in-plane-out-of-plane separated representation of the different mechanical fields involved in the elastic problem (displacements, strains and stresses) within the Proper Generalized Decomposition - PGD - framework (revisited in the next section) that computes the 3D solution as a series of 2D problems for calculating the in-plane contributions and 1D problems for computing the out-of-plane contribution. Thus, even if thousands of nodes are employed for discretizing the laminate thickness, the numerical complexity remains the one related to the solution of the $2 \mathrm{D}$ problems and consequently the one related to the in-plane mesh. This decomposition allows zooming the solution evolution through the thickness by using an extremely fine mesh along the laminate thickness with an affordable computational cost.

The paper is structured as follows: the main ingredients of the in-plane-out-of-plane PGD representation is revisited in the next section. Section 3 defined the structural systems and the modeling hypotheses. Then, Section 4 presents the simulation results for the different ply arrangements and thicknesses. Finally, Section 5 focusses on two arrangements $[45 / 0 /-45 / 90]_{1 S}$ and $\left[45_{8} / 0_{8} /-45_{8} / 90_{8}\right]_{1 S}$, having the same total thickness, the same global orientation through the thickness but different arrangements. The comparison of elastic solution for both arrangements allows to conclude on the origin of stiffness performance enhancement when using thin-ply composite laminates.

\section{Revisiting the in-plane-out-of-plane separated representations}

A new discretization technique, the so-called Proper Generalized Decomposition - PGD -, based on the use of separated representations was proposed some years ago for addressing multidimensional models suffering the so-called curse of dimensionality, where standard mesh-based techniques fail $[2,3]$. The curse of dimensionality was circumvented thanks to 
those separated representations that transformed the solution of a multidimensional problem into a sequence of lower dimensional problems. The interested reader can refer to the recent reviews $[7,8,9]$ and the references therein.

A direct consequence was separating the physical space. Thus in plate domains an inplane-out-of-plane decomposition was proposed for solving 3D flows occurring in RTM Resin Transfer Moulding - processes [8], then for solving elasticity problems in plates [4, 14] and shells [5] and flows problems [12, 13]. In those cases the 3D solution was obtained from the solution of a sequence of $2 \mathrm{D}$ problems (the ones involving the in-plane coordinates) and $1 \mathrm{D}$ problems (the ones involving the coordinate related to the plate thickness). The most outstanding advantage is that $3 \mathrm{D}$ solutions can be obtained with a computational cost characteristic of standard 2D solutions.

In [4] we considered the in-plane-out-of-plane decomposition for solving 3D elastic problems in plate geometries. The elastic problem was defined in a plate domain $\Xi=\Omega \times \mathcal{I}$ with $(x, y) \in \Omega, \Omega \subset \mathbb{R}^{2}$ and $z \in \mathcal{I}, \mathcal{I}=[0, H] \subset \mathbb{R}$, being $H$ the plate thickness. The separated representation of the displacement field $\mathbf{u}=\left(u_{1}, u_{2}, u_{3}\right)$ reads:

$$
\mathbf{u}(x, y, z)=\left(\begin{array}{l}
u_{1}(x, y, z) \\
u_{2}(x, y, z) \\
u_{3}(x, y, z)
\end{array}\right) \approx \sum_{i=1}^{N}\left(\begin{array}{c}
P_{1}^{i}(x, y) \cdot T_{1}^{i}(z) \\
P_{2}^{i}(x, y) \cdot T_{2}^{i}(z) \\
P_{3}^{i}(x, y) \cdot T_{3}^{i}(z)
\end{array}\right),
$$

where $P_{k}^{i}, k=1,2,3$, are functions of the in-plane coordinates $(x, y)$ whereas $T_{k}^{i}, k=1,2,3$, are functions involving the thickness coordinate $z$. In [4] we compared the first modes of such separated representations with the kinematic hypotheses usually considered in plate theories.

Expression (1) can be written in a more compact form by using the Hadamard (componentto-component) product:

$$
\mathbf{u}(x, y, z) \approx \sum_{i=1}^{N} \mathbf{P}^{i}(x, y) \circ \mathbf{T}^{i}(z)
$$

where vectors $\mathbf{P}^{i}$ and $\mathbf{T}^{i}$ contain functions $P_{k}^{i}$ and $T_{k}^{i}$ respectively.

Because neither the number of terms in the separated representation of the displacement field nor the dependence on $x_{3}$ of functions $T_{k}^{i}$ are assumed a priori, the approximation is flexible enough for representing the fully 3D solution, being obviously more general than theories assuming particular a priori evolutions in the thickness direction $z$.

Let's consider a linear elasticity problem on a plate domain $\Xi=\Omega \times \mathcal{I}$. The weak form using the so-called Voigt notation, reads:

$$
\int_{\Xi} \boldsymbol{\epsilon}\left(\mathbf{u}^{*}\right)^{T} \cdot(\mathbf{K} \cdot \boldsymbol{\epsilon}(\mathbf{u})) d \mathbf{x}=\int_{\Xi} \mathbf{u}^{*} \cdot \mathbf{f}_{d} d \mathbf{x}+\int_{\Gamma_{N}} \mathbf{u}^{*} \cdot \mathbf{F}_{d} d \mathbf{x}, \quad \forall \mathbf{u}^{*}
$$

where $\mathbf{K}$ is the generalized $6 \times 6$ Hooke's stiffness tensor, $\mathbf{f}_{d}$ represents the volumetric body forces while $\mathbf{F}_{d}$ represents the traction applied on the boundary $\Gamma_{N}$. The separation of variables introduced in Eq. (1) yields the following expression for the derivatives of the 
displacement components $u_{i}, i=1,2,3$ :

$$
\begin{aligned}
\frac{\partial u_{i}}{\partial x} & \approx \sum_{k=1}^{k=N} \frac{\partial P_{i}^{k}}{\partial x} \cdot T_{i}^{k}, \\
\frac{\partial u_{i}}{\partial y} & \approx \sum_{k=1}^{k=N} \frac{\partial P_{i}^{k}}{\partial y} \cdot T_{i}^{k},
\end{aligned}
$$

and

$$
\frac{\partial u_{i}}{\partial z} \approx \sum_{k=1}^{k=N} P_{i}^{k} \cdot \frac{\partial T_{i}^{k}}{\partial z},
$$

from which we the separated vector form of the strain tensor $\boldsymbol{\epsilon}$ is obtained:

$$
\boldsymbol{\epsilon}(\mathbf{u}(x, y, z)) \approx \sum_{k=1}^{N}\left(\begin{array}{c}
\frac{\partial P_{1}^{k}}{\partial x} \cdot T_{1}^{k} \\
\frac{\partial P_{2}^{k}}{\partial y} \cdot T_{2}^{k} \\
P_{3}^{k} \cdot \frac{\partial T_{3}^{k}}{\partial z} \\
\frac{\partial P_{1}^{k}}{\partial y} \cdot T_{1}^{k}+\frac{\partial P_{2}^{k}}{\partial x} \cdot T_{2}^{k} \\
\frac{\partial P_{3}^{k}}{\partial x} \cdot T_{3}^{k}+P_{1}^{k} \cdot \frac{\partial T_{1}^{k}}{\partial z} \\
\frac{\partial P_{3}^{k}}{\partial y} \cdot T_{3}^{k}+P_{2}^{k} \cdot \frac{\partial T_{2}^{k}}{\partial z}
\end{array}\right)
$$

The separated representation construction proceeds by computing a term of the sum at each iteration. Assuming that the first $n-1$ modes (terms of the finite sum) of the solution were already computed, $\mathbf{u}^{n-1}(x, y, z)$ with $n \geq 1$, the solution enrichment reads:

$$
\mathbf{u}^{n}(x, y, z)=\mathbf{u}^{n-1}(x, y, z)+\mathbf{P}^{n}(x, y) \circ \mathbf{T}^{n}(z)
$$

where both vectors $\mathbf{P}^{n}$ and $\mathbf{T}^{n}$ containing functions $P_{i}^{n}$ and $T_{i}^{n}(i=1,2,3)$ depending on $(x, y)$ and $z$ respectively, are unknown at the present iteration. The test function $\mathbf{u}^{*}$ reads $\mathbf{u}^{*}=\mathbf{P}^{*} \circ \mathbf{T}^{n}+\mathbf{P}^{n} \circ \mathbf{T}^{*}$.

The introduction of Eq. (8) into (3) results in a non-linear problem. We proceed by considering the simplest linearization strategy, an alternated directions fixed point algorithm, that proceeds by calculating $\mathbf{P}^{n, k}$ from $\mathbf{T}^{n, k-1}$ and then by updating $\mathbf{T}^{n, k}$ from the just calculated $\mathbf{P}^{n, k}$ where $k$ refers to the step of the non-linear solver. The iteration procedure continues until convergence, that is, until reaching the fixed point $\| \mathbf{P}^{n, k} \circ \mathbf{T}^{n, k}-\mathbf{P}^{n, k-1} \circ$ $\mathbf{T}^{n, k-1} \|<\epsilon$, that results in the searched functions $\mathbf{P}^{n, k} \rightarrow \mathbf{P}^{n}$ and $\mathbf{T}^{n, k} \rightarrow \mathbf{T}^{n}$. Then, the enrichment step continues by looking for the next mode $\mathbf{P}^{n+1} \circ \mathbf{T}^{n+1}$. The enrichment stops when the model residual becomes small enough.

When $\mathbf{T}^{n}$ is assumed known, we consider the test function $\mathbf{u}^{\star}$ given by $\mathbf{P}^{\star} \circ \mathbf{T}^{n}$. By introducing the trial and test functions into the weak form and then integrating in $\mathcal{I}$ because all the functions depending on the thickness coordinate are known, we obtain a $2 \mathrm{D}$ weak formulation defined in $\Omega$ whose discretization (by using a standard discretization strategy, e.g. finite elements) allows computing $\mathbf{P}^{n}$. 
Analogously, when $\mathbf{P}^{n}$ is assumed known, the test function $\mathbf{u}^{\star}$ is given by $\mathbf{P}^{n} \circ \mathbf{T}^{\star}$. By introducing the trial and test functions into the weak form and then integrating in $\Omega$ because all the functions depending on the in-plane coordinates $(x, y)$ are at present known, we obtain a 1D weak formulation defined in $\mathcal{I}$ whose discretization (using any technique for solving standard ODE equations) allows computing $\mathbf{T}^{n}$.

As discussed in [4] this separated representation allows computing 3D solutions while keeping a computational complexity characteristic of 2D solution procedures. If we consider a hexahedral domain discretized using a regular structured grid with $N_{x}, N_{y}$ and $N_{z}$ nodes in the $x, y$ and $z$ directions respectively, usual mesh-based discretization strategies imply a challenging issue because the number of nodes involved in the model scales with $N_{x} \cdot N_{y} \cdot N_{z}$, however, by using the separated representation and assuming that the solution involves $N$ modes, one must solve about $N \cdot 2 \mathrm{D}$ problems related to the functions involving the in-plane coordinates $(x, y)$ and the same number of $1 \mathrm{D}$ problems related to the functions involving the thickness coordinate $z$. The computing time related to the solution of the one-dimensional problems can be neglected with respect to the one required for solving the two-dimensional ones. Thus, the resulting complexity scales as $N \cdot N_{x} \cdot N_{y}$. By comparing both complexities we can notice that as soon as $N_{z} \gg N$ the use of separated representations leads to impressive computing time savings, making possible the solution of models never until now solved, and even using light computing platforms. In Fig. 1 PGD and fully 3D solutions are compared from the point of view of the computational efforts.

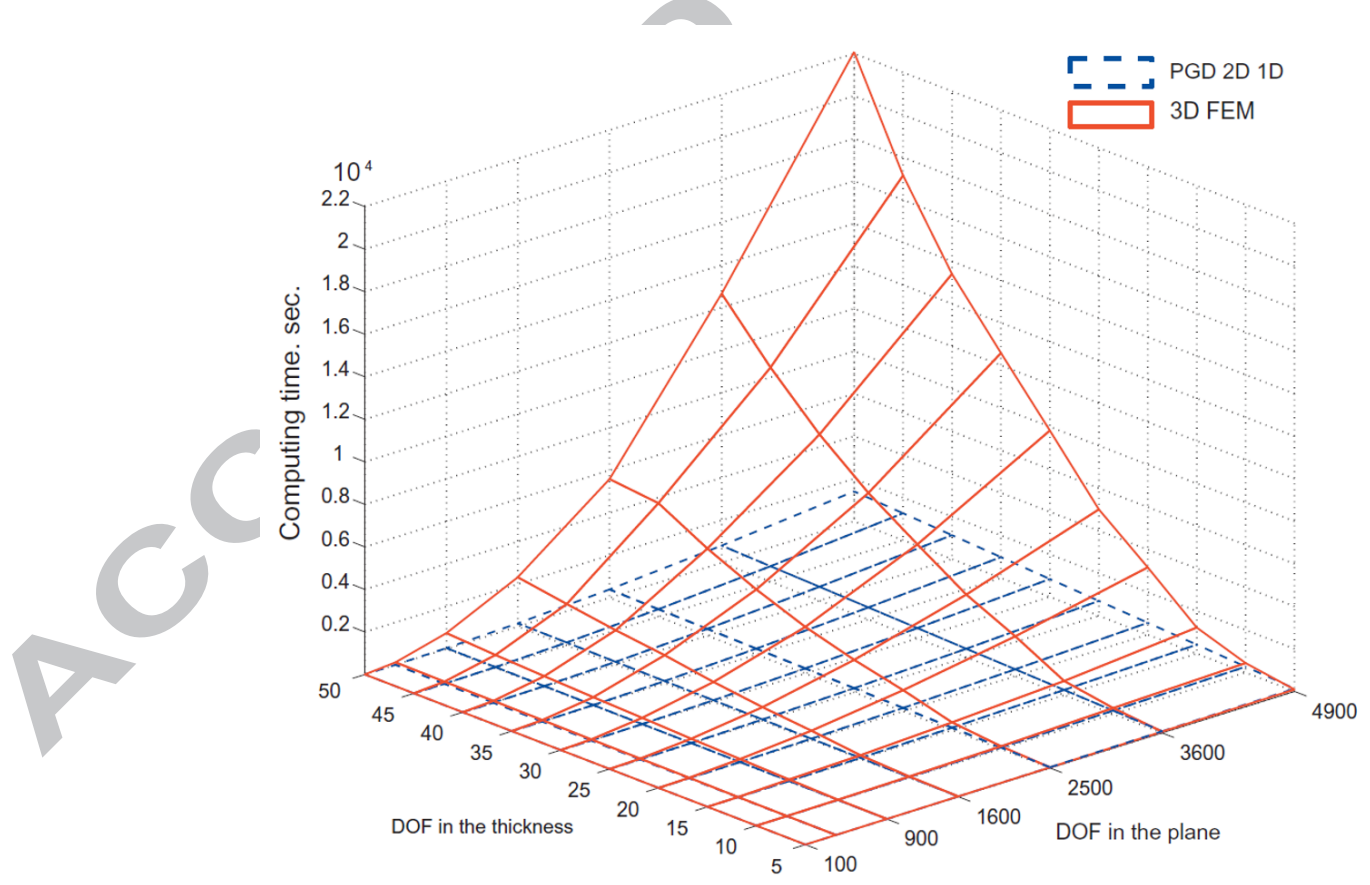

Figure 1: CPU time for solving a elastic problelm defined in a plate using the 2D/1D PGD separated representation and the fully 3D FEM (credits [14])

When addressing laminates the only difference is the necessity of performing an in-planeout-of-plane decomposition of the Hooke's tensor K. Assuming the laminate is made of $\mathcal{P}$ 
plies each one characterized by an elastic tensor $\mathbf{K}_{p}$, and denoting by $\chi_{p}(z)$ the characteristic function taking a unit value for the z-coordinate related to the $p$-ply, vanishing elsewhere, the laminate Hooke tensor can be written as

$$
\mathbf{K}=\sum_{p=1}^{\mathcal{P}} \chi_{p}(z) \mathbf{K}_{p} .
$$

he PGD framework, and particularly its in-plane-out-of-plane separated representation just described, allows resolving the mechanical fields beyond the usual discretization techniques capabilities. Thus, the simulation performed and discussed below, cannot be accomplished using more experienced simulation techniques. The PGD becomes a sort of numerical microscope able to access to scales out of reach for other numerical strategies, allowing for a fine enough analysis of stresses and strains existing in thin-ply composites.

\section{Materials}

In order to model the composite laminate as accurately as possible a cross section of it was analyzed. It was observed that interfaces between plies are richer in polymer than in the unidirectional plies as depicted in Fig. 2. Based on those observations each ply is represented by a core layer with the orientation of fibers inside denoted by the angle $\theta$ covered on both faces by two thin layers of pure matrix, as depicted in Fig. 3. The skin layers represents $1 \%$ of the total ply thickness, denoted $t_{p l y}$.

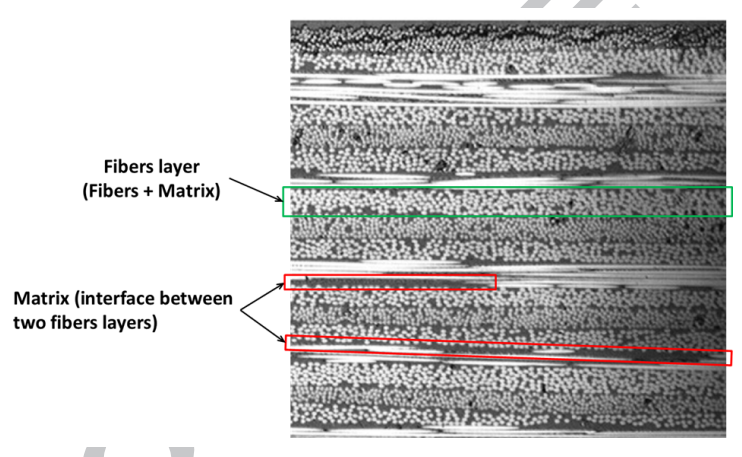

Figure 2: Composite laminate cross section (credits from [15])

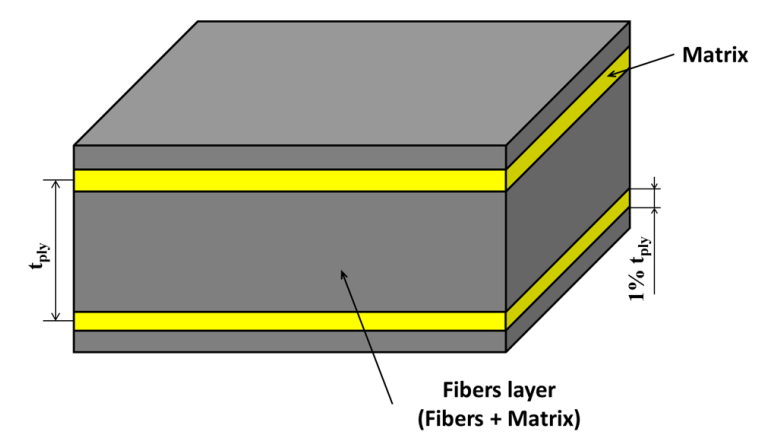

Figure 3: Laminate representation for the calculation

Simulations carried out in this study concern high modulus carbon epoxy composite laminates widely encountered in aerospace applications. The mechanical properties of the carbon-epoxy prepreg and the epoxy matrix are given in Tables 1 and 2 respectively, where indexes $\bullet_{l}$ denote the fibers direction and $\bullet_{t}$ its transverse direction. 


\begin{tabular}{lcccc}
\hline & $E_{l}(\mathrm{MPa})$ & $E_{t}(\mathrm{MPa})$ & $G_{l t}(\mathrm{MPa})$ & $\nu_{l t}$ \\
Layer of fibers & 235755 & 5357 & 3653 & 0.336 \\
\hline
\end{tabular}

Table 1: Mechanical properties of homogenized carbon-epoxy prepreg for a $60 \%$ of fiber volume fraction [11]

\begin{tabular}{cccc}
\hline & $E(\mathrm{MPa})$ & $G_{l t}(\mathrm{MPa})$ & $\nu$ \\
Epoxy & 4500 & 1600 & 0.4 \\
\hline
\end{tabular}

Table 2: Mechanical properties of epoxy [11]

\section{Numerical analysis}

We consider different stacking arrangements, all of them having the same total thickness:

- $[45 / 0 /-45 / 90]_{N S}$, with $N=1, \cdots, 10 \& 20$; considered as reference in the following simulations

- $[90 /-45 / 0 / 45]_{N S}$, with $N=1,4 \& 8$;

- $[0 / 90]_{N S}$, with $N=1,5,10 \& 20$.

The resulting 3D plates are clamped at their edges and a concentrated force $(\mathbf{F}=1 \mathrm{kN})$ is applied at the center of the upper surfaces as illustrated in Fig. 4. Simulations were performed by considering a fine enough mesh, especially along the laminate thickness, in order to capture all the details related to the through-thickness evolution of the different mechanical fields: displacement, strain and stresses and the inter-ply interface conditions. For that purpose the in-plane mesh consisted of 12500 elements whereas in the thickness direction 4 elements were considered in each epoxy layer and 20 in each prepreg layer, leading to 24 elements per ply.

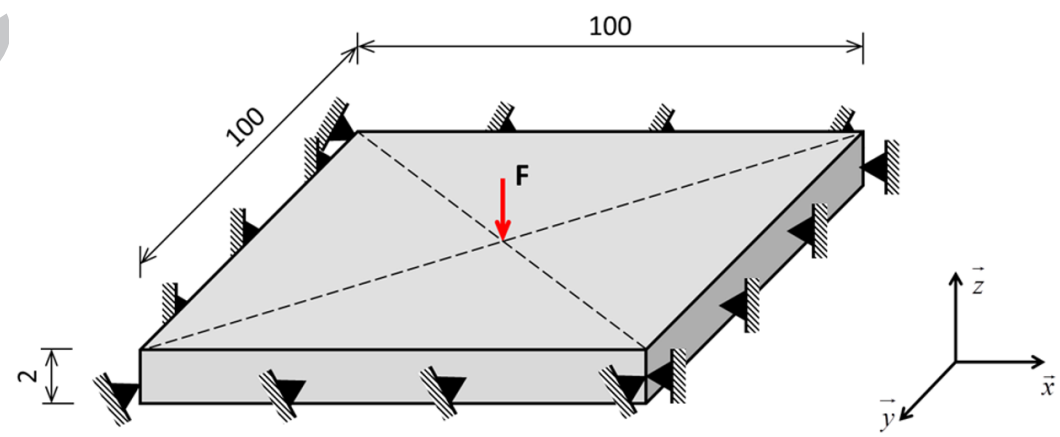

Figure 4: Simulated plate, loading case and applied boundary conditions 


\subsection{Evaluating the composite laminates stiffness}

To evaluate the effect of the ply thickness on the laminate stiffness we compute the deflection (f) at the center of the plate for the same applied force. Results are depicted in Figs. 5, 6 and 7. A decrease of the deflection is clearly noticed for all the stacking arrangements when increasing $N$, revealing the stiffness increasing with the plies thickness decreasing, that reaches the value of $10 \%$ for the stacking $[45 / 0 /-45 / 90]_{N S}$, in agreement with the experimental findings reported in $[17,18]$. In can be also noticed in those figures that the deflection (and consequently the stiffness) reaches an asymptotic constant value, that reveals the existence of an homogenized behavior for small enough ply thickness.

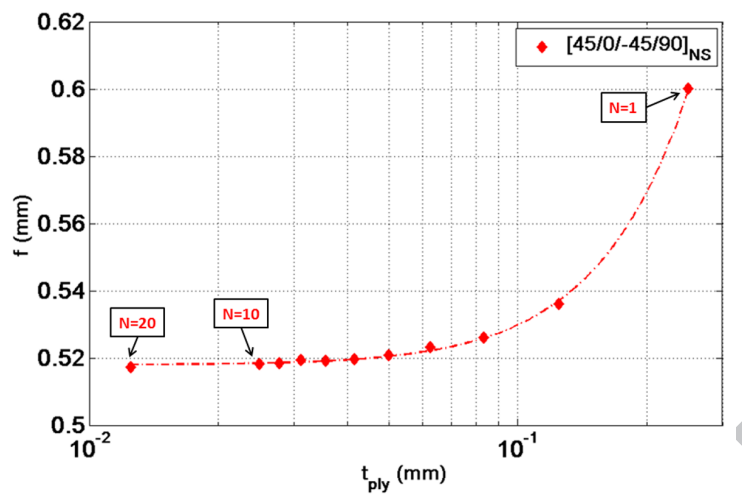

Figure 5: Deflection (f) versus ply thickness $\left(t_{p l y}\right):[45 / 0 /-45 / 90]_{N S}$ stacking $(N=1, \cdots, 10 \& 20)$

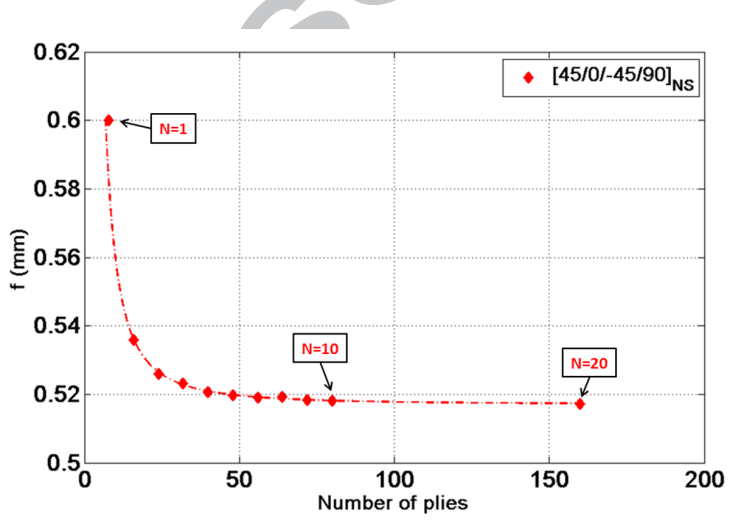

Figure 6: Deflection (f) versus number of plies: $[45 / 0 /-45 / 90]_{N S}$ stacking $(N=1, \cdots, 10 \& 20)$

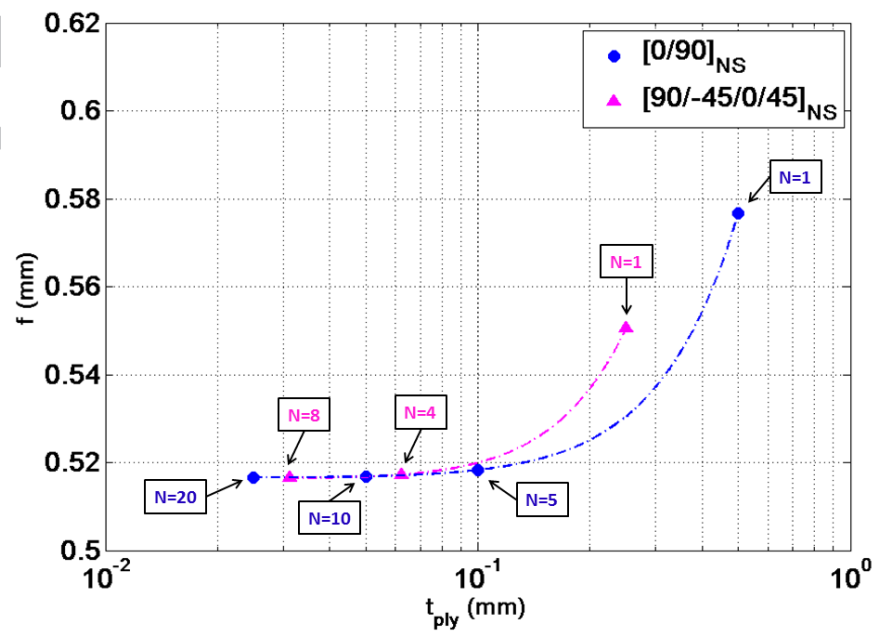

Figure 7: Deflection (f) evolution versus ply thickness $\left(t_{p l y}\right)$ for two different arrangements 


\section{Discussion on the origin of the stiffness performance enhancement}

In order to conclude on the physical mechanisms leading to the stiffness increase we consider two particular laminates: $[45 / 0 /-45 / 90]_{1 S}$ and $\left[45_{8} / 0_{8} /-45_{8} / 90_{8}\right]_{1 S}$, denoted by "config.1S" and "config.8/1S" respectively. We performed similar simulations that previously, reporting the deflection for the same applied load and similar meshes. These two configurations have the same amount of fibers along each direction, the same total thickness, the only difference being the ply thickness. Each ply in the first configuration is split into 8 thinner plies with the same orientation and total thickness.

Fig. 8, 9, 10 and 11 show the through-thickness evolution at position $(x, y)=(1,1)$ of the different components of the stress tensor. Assuming the performance enhancement is due to mechanical confinement and consequently to the ply-thickness itself, these stresses should be different in both configurations. However, these figures reveal that stresses are almost identical, which provides evidence that the stiffness increase is not intrinsically due to the ply-thickness effect.

Thus, it results from the above that the stiffness increase is a purely structural consequence. When using thinner plies with alternating orientations, in the space occupied by a thicker ply with a unique orientation direction, the laminate is made of many thinner plies with many orientation directions, increasing the global laminate stiffness.

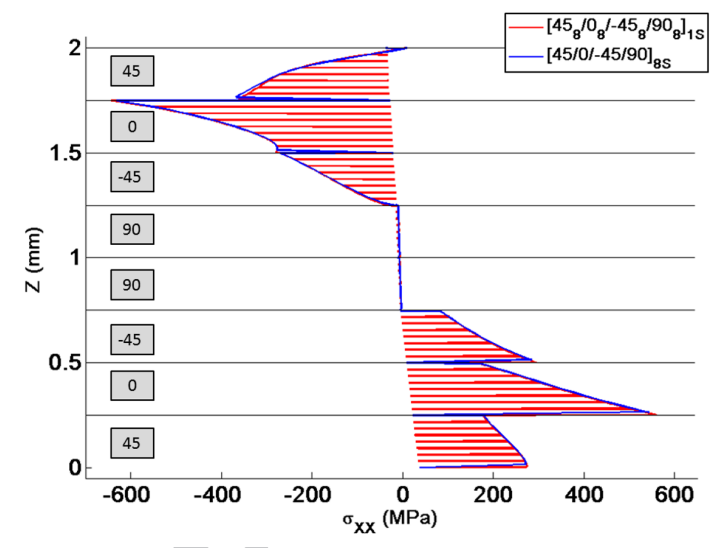

Figure 8: Evolution of $\sigma_{x x}$ through the laminate thickness

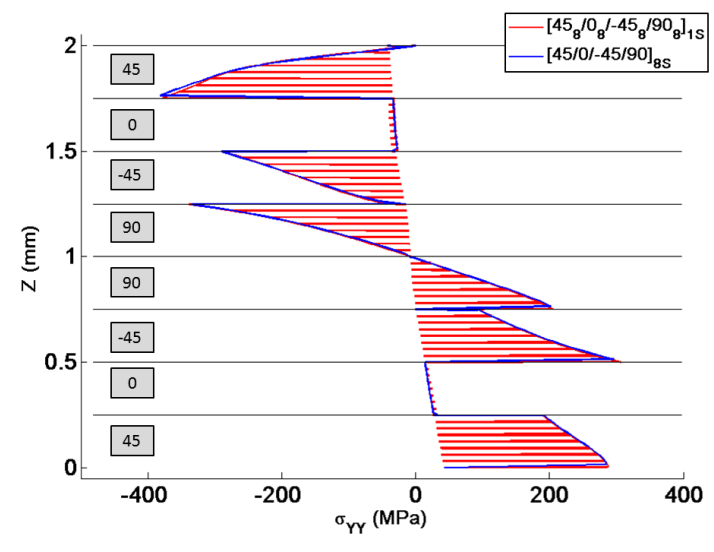

Figure 9: Evolution of $\sigma_{y y}$ through the laminate thickness 


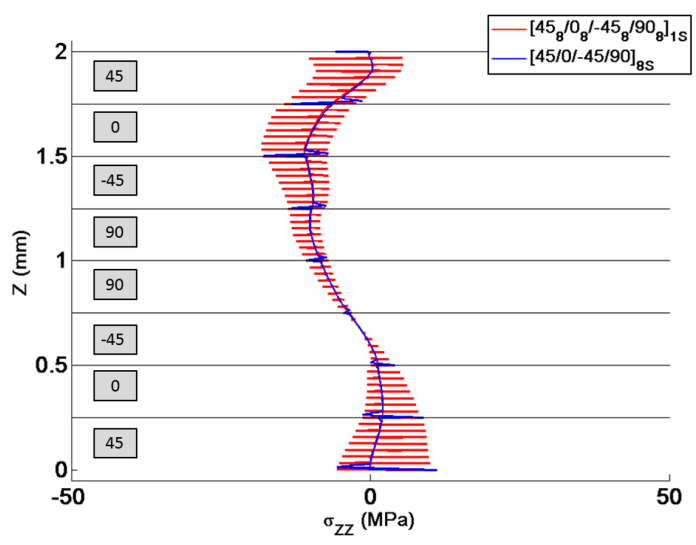

Figure 10: Evolution of the $\sigma_{z z}$ through the laminate thickness

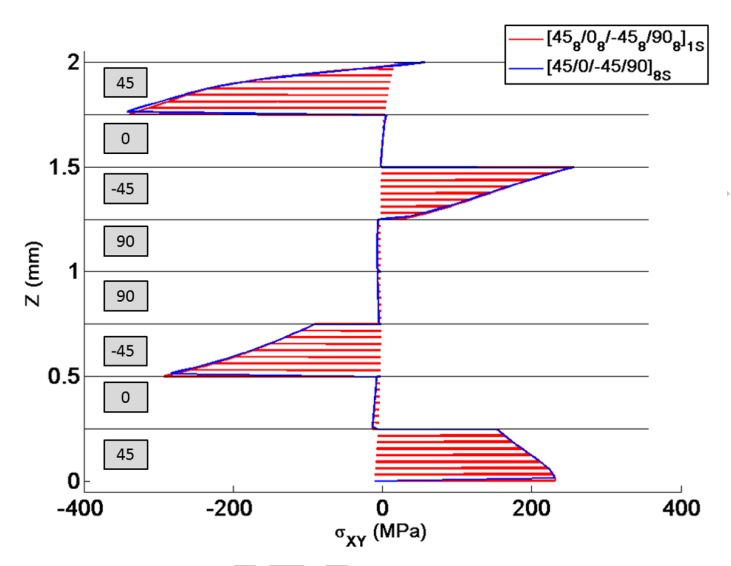

Figure 11: Evolution of the $\sigma_{x y}$ through the laminate thickness

\section{Conclusions}

This paper investigates the performance enhancement noticed in thin-ply composite laminates. The analysis is restricted to purely elastic behavior and does not consider irreversible behavior involving damage and fracture. The objective was to quantify the potential increase of the apparent laminate stiffness when decreasing the ply thickness. For computing a fine enough solution while circumventing the difficulties related to the excessive degrees of freedom of fully 3D mesh-based discretizations, we took advantage of in-plane-out-of-plane separated representations within the PGD framework that allowed capturing extremely fine details of the mechanical fields along the laminate thickness.

For the different stacking arrangements studied the apparent laminate stiffness showed an asymptotic increase as the ply thickness decreased. The second objective of this study was to elucidate the physical origin of this performance increase. A first explanation was proposed, related to the confinement effects. However, when analyzing equivalent laminates where each thick ply was split into many thinner plies (while keeping the same total thickness and reinforcement orientation) results were identical, which proves that the noticed stiffness increase is not inherently due to the ply thickness. Thus, the mechanical improvement has its origin in a purely structural effects induced by the stacking arrangement as discussed in the above section.

The case of inelastic regimes should be addressed to provide a more comprehensive analysis of some experimental findings.

\section{Bibliography}

[1] R. Amacher, J. Cugnoni, J. Botsis, L. Sorensen, W. Smith, C. Dransfeld. Thin ply composites: Experimental characterization and modeling of size-effects, Composites Science and Technology, 101, 121-132, 2014. 
[2] A. Ammar, B. Mokdad, F. Chinesta, R. Keunings. A new family of solvers for some classes of multidimensional partial differential equations encountered in kinetic theory modeling of complex fluids. J. Non-Newtonian Fluid Mech., 139, 153-176, 2006.

[3] A. Ammar, B. Mokdad, F. Chinesta, R. Keunings. A new family of solvers for some classes of multidimensional partial differential equations encountered in kinetic theory modeling of complex fluids. Part II: transient simulation using space-time separated representations. J. Non-Newtonian Fluid Mech., 144, 98-121, 2007.

[4] B. Bognet, A. Leygue, F. Chinesta, A. Poitou and F. Bordeu, Advanced simulation of models defined in plate geometries: 3D solutions with 2D computational complexity, Computer Methods in Applied Mechanics and Engineering, 201, 1-12, 2012.

[5] B. Bognet, A. Leygue, F. Chinesta. Separated representations of 3D elastic solutions in shell geometries. Advanced Modelling and Simulation in Engineering Sciences, 2014, 1:4, http://www.amses-journal.com/content/1/1/4

[6] W-H. Chen, S-S. Lee. Numerical and experimental failure analysis of composite laminates with bolted joints under bending loads, Journal of composite materials, 29:1, 15-36, 1995.

[7] F. Chinesta, A. Ammar and E. Cueto, Recent advances and new challenges in the use of the Proper Generalized Decomposition for solving multidimensional models, Archives of Computational Methods in Engineering, 17, 327-350, 2010.

[8] F. Chinesta, A. Ammar, A. Leygue, R. Keunings. An overview of the Proper Generalized Decomposition with applications in computational rheology. Journal of Non Newtonian Fluid Mech., 166, 578-592, 2011.

[9] F. Chinesta, P. Ladeveze and E. Cueto, A short review in model order reduction based on Proper Generalized Decomposition, Archives of Computational Methods in Engineering, 18, 395-404, 2011.

[10] A. Evcil. Simulation of three dimensional progressive damage in composite laminates, Intl. Journal of Mechanics, 4:2, 67-75, 2008.

[11] D. Gay. Matériaux composites, Hermes, 1991.

[12] Ch. Ghnatios, F. Chinesta, Ch. Binetruy. The Squeeze Flow of Composite Laminates. International Journal of Material Forming, 8, 73-83, 2015.

[13] Ch. Ghnatios, E. Abisset-Chavanne, Ch. Binetruy, F. Chinesta et S. Advani. 3D modeling of squeeze flow of multiaxial laminates. Journal of Non-Newtonian Fluid Mechanics, 234, 188-200, 2016. 
[14] E. Giner, B. Bognet, J.J. Rodenas, A. Leygue, F.J. Fuenmayor, F. Chinesta. The proper generalized decomposition (PGD) as a numerical procedure to solve 3D cracked plates in linear elastic fracture mechanics, International Journal of Solids and Structures, 50:10, 1710-1720, 2013.

[15] H. Saito, M. Morita, K. Kawabe, M. Kanesaki, H. Takeuchi, M. Tanaka, I. Kimpara. Effect of ply-thickness on impact damage morphology in CFRP laminates, Journal of Reinforced Plastics and Composites, 30:13, 1097-1106, 2011.

[16] S. Sanchez-Saez, E. Barbero, R. Zaera, C. Navarro. Compression after impact of thin composite laminates. Composites Science and Technology, 65:13, 1911-1919, 2005.

[17] S. Sihn, R.Y. Kim, K. Kawabe, S.W. Tsai. Experimental studies of thin-ply laminated composites, Composites Science and Technology, 67:6, 996-1008, 2007.

[18] T. Yokozeki, A. Kuroda, A. Yoshimura, T. Ogasawara, T. Aoki. Damage characterization in thin-ply composite laminates under out-of-plane transverse loadings, Composite Structures, 93:1, 49-57, 2010. 